\title{
Avaliação de cultivares de alface em ambiente protegido em Boa Vista, Roraima, Brasil
}

Wellington Farias ARAÚJO ${ }^{1}$, Eliander Pimentel TRAJANO², José Luiz RODRIGUES NETO³, Moisés MOURÃO JÚNIOR Paulo Roberto Valle da Silva PEREIRA ${ }^{4}$

\section{RESUMO}

O presente trabalho avaliou o desempenho de seis cultivares de alface em ambiente protegido. O delineamento experimental foi o de blocos ao acaso, com seis tratamentos e quatro repetiçōes. As cultivares de alface avaliadas foram: Hortência, Rubra, Mônica SF1, Regina de Verão, Verônica e Grandes Lagos 659. A temperatura do ar dentro do ambiente protegido oscilou entre $24,4^{\circ} \mathrm{Ce} 31,5 \mathrm{oC}$ durante o cultivo. Rubra e Grandes Lagos 659 apresentaram os melhores desempenhos, com rendimentos médios superiores a 28.000 kg.ha-1 e massa fresca por planta de 176,7 g e 184,4 g, respectivamente.

\section{PALAVRAS-CHAVE}

Lactuca sativa L., produtividade, competição de cultivares

\section{Evaluation of lettuce cultivars under protected cultivation in Boa Vista, Roraima, Brazil}

\section{ABSTRACT}

This study evaluated the growth and yield of six lettuce cultivars under protected cultivation. The experimental design was randomized blocks with six treatments and four replications. The cultivars Hortencia, Rubra, Monica SF1, Regina de Verão, Veronica and Grandes Lagos 659 were evaluated. The air temperature under protected cultivation oscillated between 24,40C and 31,5oC during the experimental period. Rubra and Grandes Lagos 659 showed the best performance with yields superior to 28,000 kg.ha-1 and fresh weight of 176,7g and $184,4 \mathrm{~g}$, respectively.

\section{KEY WORDS}

Lactuca sativa L., yield, cultivar competition

\footnotetext{
1 Universidade Federal de Roraima - UFRR, Centro de Ciências Agrárias - CCA, Av. Enê Garcez, 2413 - Aeroporto, 69304-000 Boa Vista, Roraima. Fone/Fax: (95) 621-3112. e-mail: wellington.farias@uol.com.br

2 Secretaria Municipal de Agricultura de Boa Vista,Aluno do Programa de Pós-Graduação em Recursos Naturais

${ }^{3}$ Bolsista de PIBIC/CNPq

${ }^{4}$ Embrapa Centro de Pesquisa Agroflorestal - CPAF/RR, Caixa Postal 133, 69034-970 Boa Vista, Roraima
} 
A Prefeitura de Boa Vista implantou o "Projeto Estufa" para incentivar o cultivo de diversas hortaliças em ambiente protegido, objetivando atender grande parte da demanda local de hortaliças em quantidade e qualidade. Dentre as hortaliças cultivadas, a alface tem merecido destaque, entretanto problemas de adaptação de cultivares a ambientes com temperaturas elevadas, problemas fitossanitários e de manejo na irrigação são freqüentes.

$\mathrm{Na}$ região amazônica, trabalhos com alface são raros (Oliveira \& Braid, 1985; Freitas Luz, 1990; Cardoso \& Lourenço, 1990) e foram realizados em condições de campo. Não se conhecem estudos sobre essa hortaliça em cultivo protegido em Roraima. $\mathrm{O}$ objetivo do trabalho foi identificar cultivares de alfaces aptas ao cultivo sob condição de ambiente protegido em Boa Vista, Roraima.

O experimento foi conduzido em ambiente protegido no Campus do Cauamé, pertencente à Universidade Federal de Roraima (UFRR), em Boa Vista (2o49'11"N, 60o40'24"W e 90 m). Segundo a classificação de Köppen, o clima da região é do tipo Awi, com duas estaçôes climáticas bem definidas, uma chuvosa (abril-setembro) e outra seca (outubro-março) (Araújo et al., 2001). A área experimental foi constituída por uma estufa, modelo capela modificada, com $50 \mathrm{~m}$ de comprimento e $7 \mathrm{~m}$ de largura, com $3 \mathrm{~m}$ de pé-direito e coberta com película de polietileno transparente de baixa densidade aditivada anti-UV, de $100 \mu \mathrm{m}$ de espessura. O solo da área experimental é classificado como Latossolo Amarelo, textura franco-argilo-arenosa. A adubação constou da aplicação de 100 g.m-2 de calcário dolomítico um mês antes do transplante, 50 g.m-2 de P2O5 na forma de supersimples, $15 \mathrm{~g} . \mathrm{m}-2$ de $\mathrm{K}_{2} \mathrm{O}$ aplicado na forma de cloreto de potássio, $60 \mathrm{~kg}$.ha-1 de esterco bovino e $1 \mathrm{~g} . \mathrm{m}-2$ de bórax como adubação de base. A aplicação de nitrogênio (3,0 g.m-2 de uréia) foi feita via fertirrigação aos 4, 6, 8 e 13 dias após o transplante (DAT).

O delineamento experimental foi o de blocos ao acaso, com quatro repetiçōes, onde foram avaliadas seis cultivares de alface: Hortência, Mônica SF1 e Verônica, do grupo crespa; Rubra e Regina de Verão do grupo lisa; e alface americana Grandes Lagos 659. O transplante foi realizado quando as mudas tinham quatro folhas definitivas, num espaçamento de $0,25 \times 0,25 \mathrm{~m}$. Cada parcela experimental media 4,0 $\mathrm{m} 2$ de área $(1,0 \times 4,0 \mathrm{~m})$ e foi constituída por 64 plantas.

A irrigação foi feita com o uso de fitagotejantes, com emissores a cada $20 \mathrm{~cm}$ e com vazões de $11 . \mathrm{h}-1$ a $71 \mathrm{kPa}$ de pressão de serviço. A reposição foi diária com base na leitura diária do tanque Classe A, colocando-se 100\% da Evaporação do Tanque Classe A (ECA). O tanque foi posicionado dentro da estufa na parte central e sobre um estrado de madeira com $15 \mathrm{~cm}$ de altura.

Foram analisados eficiência do uso da água, número de folhas, área foliar, massa fresca da parte aérea e os rendimentos da cultura. A eficiência de uso de água foi determinada em função da relaçāo entre os valores de rendimento e a lâmina de irrigação aplicada.
Para determinação da área foliar, aos 20 DAT, todas as folhas de coloração verde de duas plantas representativas de cada parcela foram medidas utilizando-se um integrador óptico de área LICOR (area meter - model li 3000, Lincoln, Nebraska, USA.). Para obtenção da massa fresca da parte aérea, número de folhas e rendimento, oito plantas de cada parcela foram avaliadas logo após a colheita. Para o cálculo do rendimento, os dados de massa fresca por planta foram transformados em massa por área (kg.ha1), considerando a densidade de plantio utilizada.

As análises estatísticas foram feitas com auxílio dos pacotes estatísticos SAS System e Statistica 5.5. Os valores médios das variáveis estudadas foram ordenados por meio do teste de comparação múltipla de Duncan, considerando o nível de significância de $5 \%$.

As cultivares Grandes Lagos (144,6 kg.ha-1.mm-1) e Rubra (138,6 kg.ha-1.mm-1) apresentaram valores de eficiência de uso de água significativamente superiores em relação às demais cultivares (Tabela 1), acompanhando a mesma tendência do rendimento, já que não houve aplicação de água diferenciada entre as cultivares. Quanto ao número de folhas por planta, destacou-se a "Rubra", sendo significativamente superior às demais cultivares. A maior quantidade de folhas por planta ( 32 folhas.plantas-1) e de área foliar $(2.362,4 \mathrm{~cm} 2)$ contribuíram para a sua maior massa fresca. Isto é um indicativo de que "Rubra" apresenta boa adaptação ao ambiente e/ou menor necessidade de graus dia do que as outras cultivares para emissão de novas folhas, o que acabou refletindo em maior produção. Vale destacar que o rendimento de "Grandes Lagos" não diferiu da "Rubra", embora tenha apresentado um menor número de folhas e área foliar, demonstrando uma maior adaptação ao ambiente protegido.

As cultivares Grandes Lagos (184,38 g) e Rubra (176,66 g) apresentaram maior matéria fresca por planta, sendo significativamente superiores as outras cultivares testadas (Tabela 1). Para o rendimento total de massa fresca, sobressaíram-se

Tabela 1 - Eficiência do uso de água (EUA), número de folhas (NF), área foliar (AF), massa fresca (MF) e rendimento de seis cultivares de alface cultivadas em ambiente protegido em Boa Vista, Roraima.

\begin{tabular}{|c|c|c|c|c|c|}
\hline Cultivares & 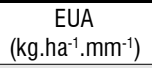 & NF & $\operatorname{AF}\left(\mathrm{cm}^{2}\right)$ & $\mathrm{MF}(\mathrm{g})$ & $\begin{array}{c}\text { RENDIMENTO } \\
\left(\mathrm{kg}^{2} \mathrm{ha}^{-1}\right)\end{array}$ \\
\hline Hortência & $107,18 \mathrm{c}$ & $12,8 \mathrm{bc}$ & $1120,7 \mathrm{c}$ & $136,7 \mathrm{c}$ & $21.265 c$ \\
\hline Rubra & $138,56 a$ & $32,5 a$ & $2362,4 a$ & $176,7 a$ & $28.266 a b$ \\
\hline Mônica SF1 & $111,31 b c$ & $13,2 b c$ & $890,7 \mathrm{c}$ & $141,9 b c$ & $22.707 \mathrm{c}$ \\
\hline $\begin{array}{l}\text { Regina de } \\
\text { Verão }\end{array}$ & $83,3 d$ & $12,5 \mathrm{c}$ & $\star * \star *$ & $106,2 d$ & $16.994 d$ \\
\hline Verônica & $123,39 b$ & $12,9 \mathrm{bc}$ & $1.079,3 \mathrm{c}$ & $157,3 b$ & $25.171 \mathrm{bc}$ \\
\hline $\begin{array}{c}\text { Grandes } \\
\text { Lagos }\end{array}$ & $144,61 a$ & $13,7 \mathrm{~b}$ & $1.516,6 \mathrm{~b}$ & $184,4 \mathrm{a}$ & $29.501 a$ \\
\hline Média & 118,06 & 16,3 & & 150,5 & 24.084 \\
\hline
\end{tabular}

* Valores seguidos pela mesma letra, na vertical, não diferem significativamente, segundo o teste de Duncan em nível de $5 \%$

${ }_{* \star}$ A área foliar não foi medida, pois a maioria das plantas já estava pendoando. 
“Grandes Lagos” e "Rubra”, esta, entretanto, não apresentou rendimentos significativamente superiores a "Verônica". Vale destacar que em Boa Vista os horticultores preferem utilizar cultivares de alface crespa, sendo "Verônica" a mais usada. Os rendimentos obtidos foram superiores aos obtidos por Freitas Luz (1990) em Roraima e por Cardoso \& Lourenço (1990) em Manaus.

As cultivares americanas “Grandes Lagos", Lisa "Rubra” e Crespa "Verônica” são recomendadas para o cultivo em ambiente protegido em Boa Vista, Roraima.

\section{AGRADECIMENTOS}

À Prefeitura Municipal de Boa Vista, Roraima, pela concessão de grande parte da infra-estrutura para execução do experimento, e ao CNPq pela concessão da Bolsa PIBIC.

\section{BIBLIOGRAFIA CITADA}

Araújo, W.F.; Andrade Júnior, A.S.; Medeiros, R.D.; Sampaio, R.A. 2001. Precipitação pluviométrica provável em Boa Vista, Estado de Roraima, Brasil. Revista Brasileira de Engenharia Agrícola e Ambiental, 5(3): 563-567.

Cardoso, M.O.; Lourenço, J.N.P. 1990. Produtividade de alface (Lactuca sativa) sob cobertura plástica e a céu aberto, no período chuvoso de Manaus. Embrapa/Centro de Pesquisa Agroflorestal da Amazônia Ocidental, Manaus. (Pesquisa em Andamento, 4)

Freitas Luz, F.J. 1990. Avaliação de cultivares de alface de folhas crespas e alternativas de adubação para o cerrado de Roraima. Embrapa/UEPAE, Boa Vista. (Comunicado Técnico, 1).

Oliveira, J.M.F.; Braid, A.R.A. 1985. Introdução e avaliação de cultivares de alface em Roraima. Embrapa/UEPAE, Boa Vista. (Pesquisa em andamento, 5).

Recebido em 06/10/2006

Aceito em 16/05/2007 
